\title{
A FUNÇÃO LÓGICA DESEMPENHADA PELAS FOTOGRAFIAS NOS PENSAMENTOS ACERCA DOS OBJETOS FOTOGRAFADOS ${ }^{1}$
}

Guilherme Ghisoni da Silva (UFG) ${ }^{2}$

ggsilva76@gmail.com

Resumo: O objetivo deste artigo é compreender a função lógica desempenhada pelas fotografias nos pensamentos acerca de entidades conhecidas exclusivamente através de fotografias. Buscarei contrastar duas linhas interpretativas gerais: a fotografia como conhecimento por familiaridade e como conhecimento por descrição. A análise dessas linhas interpretativas levará em consideração o paralelo com as discussões sobre memórias episódicas e metafísica do tempo. Ao longo do artigo, buscarei criticar o tratamento da fotografia como familiaridade, tendo como base as ideias de John Zeimbekis. No tratamento como familiaridade, a fotografia teria uma função lógica semelhante a um demonstrativo, que apontaria para entidades particulares no passado, através da rota causal que une a fotografia ao referente. A crítica de Zeimbekis tem como ponto de partida a distinção entre o referente causal da fotografia e o seu conteúdo representacional (as propriedades visuais nela exemplificadas). A tese a ser sustentada é que o conteúdo da fotografia não seria suficiente para a determinação da identidade numérica do referente. Com isso, propõe-se o deslocamento da função lógica da fotografia da função referencial para a predicativa. A fotografia exemplificaria propriedades fenomenais atribuídas a uma entidade conhecida apenas por descrição através da fotografia.

Palavras-chave: conhecimento por familiaridade; conhecimento por descrição; pensamento singular; realismo metafísico do passado; presentismo.

\footnotetext{
${ }^{1}$ Recebido: 02-01-2016/ Aceito: 05-03-2016/Publicado on-line: 06-03-2016.

${ }^{2}$ Guilherme Guisoni da Silva é professor Adjunto III da Universidade Federal de Goiás, Goiânia, GO, Brasil.
} 


\section{INTRODUÇÃO}

O objetivo deste artigo é compreender a função lógica desempenhada pelas fotografias nos pensamentos acerca de entidades conhecidas exclusivamente através de fotografias. Será tomado como caso paradigmático fotografias de entidades particulares (objetos e pessoas), em que a fotografia poderia ser utilizada como modelo no contexto de uma predicação na qual apontaríamos para a fotografia e diríamos "este é o tal-e-tal". Buscarei contrastar duas linhas interpretativas gerais: a fotografia como conhecimento por familiaridade ("knowledge by acquaintance") e como conhecimento por descrição ("knowledge by description"). A análise dessas linhas interpretativas levará em consideração o paralelo com as discussões sobre memória episódica e metafísica do tempo. ${ }^{3}$

$\mathrm{Na}$ primeira linha interpretativa, a fotografia será concebida como uma forma de visão prostética, que permitiria ampliar espaço-temporalmente o domínio das entidades conhecidas por familiaridade. Essa concepção desenvolve uma versão fotográfica das teorias semânticas referencialistas diretas, amparada em uma teoria causal da referência. Por esse viés, a fotografia teria uma função lógica semelhante a um demonstrativo, que apontaria para entidades particulares no passado, através da rota causal que une a fotografia ao referente. Assim, a fotografia deveria possibilitar pensamentos singulares (objetos-dependentes) acerca das entidades fotografadas, uma vez que é a entidade acerca da qual pensamos, ela mesma, que nos seria dada através da

\footnotetext{
${ }^{3}$ Gostaria de agradecer aos participantes do Grupo de Estudos de Filosofia da Fotografia da FAFIL/UFG, a John Zeimbekis e a Paulo Faria, pelas interlocuções, conversas e debates, nos quais pude expor e lapidar ideias presentes neste artigo.
} 
fotografia.

Ao longo do artigo, buscarei criticar esse tratamento da fotografia como familiaridade remota, tendo como base as análises de John Zeimbekis. A crítica tem como ponto de partida a distinção entre o referente causal da fotografia e o conteúdo representacional da fotografia (as propriedades visuais nela exemplificadas). Do ponto de vista causal, a fotografia é de ("of") um objeto, mas não é necessário que a imagem presente na fotografia seja semelhante ao objeto. As propriedades visuais/fenomenais exemplificadas na foto podem corresponder ou não às propriedades do referente causal da foto. Com isso, poderemos distinguir entre as crenças meta-representacionais (acerca da história causal da fotografia) e o conteúdo da fotografia.

A tese a ser sustentada (a partir da proposta de Zeimbekis) é que o conteúdo da fotografia não seria suficiente para a determinação da identidade numérica do referente, uma vez que inúmeros objetos podem satisfazer uma mesma descrição visual. Assim, embora tenhamos, como parte das crenças meta-representacionais, a crença de que há um e somente um objeto que é o referente causal da foto (crença essa que pode ser falsa, pois a fotografia poderia ser fruto de manipulações), a percepção do conteúdo da fotografia não seria suficiente para que soubéssemos (exclusivamente através do conteúdo) acerca de qual objeto estamos pensando. Com isso, a fotografia não respeitaria o Princípio de Russell - expresso por Gareth Evans.

Por esse segundo viés, a fotografia seria uma forma de conhecimento por descrição e sua função lógica seria deslocada da função referencial para a predicativa. Ao pensarmos acerca de uma entidade conhecida por meio da fotografia, teríamos um pensamento geral, de que foi o caso que existe 
alguém (ou alguma coisa), que tem semelhantes propriedades visuais às exemplificadas na fotografia.

Por fim, explorarei algumas consequências temporais do tratamento da fotografia como conhecimento por descrição.

\section{A FOTOGRAFIA COMO FAMILIARIDADE REMOTA}

Autores como Kendall Walton (2008) e Roger Scruton (2008) concebem a fotografia como uma forma remota de conhecimento por familiaridade ("knowledge by acquaintance" em sentido russelliano) (cf. Russell 1910). A fotografia é tratada como uma visão prostética, que permite ampliar espaço-temporalmente o domínio das entidades que podemos conhecer por familiaridade (cf. Walton 2008, p. 39).

Há um profundo paralelo entre a fotografia como familiaridade remota e as concepções realistas diretas das memórias episódicas (cf. Perrin 2012, pp. 20-32). Semelhantemente ao que sustentava Bertrand Russell antes de 1913, a memória é concebida como uma forma de percepção do passado (cf. Silva 2015). Nesse caso, a memória não nos daria representações (imagens) do passado, mas um acesso cognitivo direto ao objeto passado ele mesmo. Como afirma Bertrand Russell: "a essência da memória não é constituída por uma imagem, mas por ter imediatamente diante da mente um objeto que é reconhecido como passado" (1912, p. 115). ${ }^{4}$ É esse mesmo diagnóstico que podemos encontrar em Walton acerca do estatuto da imagem fotográfica:

Com a ajuda da câmera, vemos não apenas o que está para além da

\footnotetext{
${ }^{4}$ As traduções de textos de língua estrangeira são de minha autoria.
} 
esquina e o que é distante ou pequeno; nós vemos também dentro do passado. Vemos nossos ancestrais falecidos há muito tempo quando olhamos para retratos empoeirados deles. (...) Fotografias são transparentes. Vemos o mundo através delas. (2008, p. 22)

Subjacente à concepção da fotografia como familiaridade remota (que podemos chamar, por meio do paralelo com as análises da memória episódica, de "realista direta") encontra-se a aceitação de uma forma de não-descritivismo, na qual a fotografia é concebida como um nome russeliano genuíno, que singulariza uma entidade particular, através da rota causal que a une ao referente. Desse modo, a fotografia como familiaridade remota pode ser compreendida como uma versão fotográfica da tese semântica denominada por Gareth Evans de "teoria causal da referência” (1982) (e não é sem razão que Evans denomina essa concepção de "modelo fotográfico da representação mental" (idem)). Segundo Evans, Saul Kripke teria inspirado a tese que:

Alguém usa um nome para se referir a um objeto x (...) se for possível traçar uma rota causal contínua partindo de um evento, talvez no passado distante, no qual o nome foi originalmente atribuído ao objeto x. (EVANS 1982, p. 77)

$\mathrm{Na}$ teoria causal, a referência é fixada por um batismo inicial (no qual alguém aponta para um objeto e diz, p. ex., "Aristóteles"). Esse uso do nome poderá ser passado para outros falantes e é apenas necessário que os usos futuros dos falantes façam parte de uma rota causal relacionada ao batismo inicial. Nessa concepção, a existência de uma rota causal contínua seria condição suficiente para a nomeação.

A fotografia, em decorrência de sua gênese causal, desempenharia a função lógica de nomear (apontar, 
singularizar, batizar) o referente, de modo semelhante a um nome na teoria causal da referência. ${ }^{5}$ Esse paralelo é expletivamente endossado por Walton:

Eu subscreveria a alguma variedade de teoria causal: ver algo é ter uma experiência que é causada, em certa maneira, pelo que é visto. (...) parte do que é ver algo é ter experiências visuais que são causadas por isso em uma maneira puramente mecânica. Objetos causam suas fotografias e a experiência visual dos espectadores mecanicamente, então vemos objetos através de fotografias. (2008, p. 34)

Em Roger Scruton (2008) também podemos encontrar semelhante concepção. Para Scruton, as representações têm uma dimensão intencional que estaria ausente na fotografia, pois a relação, neste caso, seria meramente causal (cf. 2008, p. 140). Isso transformaria a fotografia em uma espécie de nome russeliano genuíno, cuja função semântica seria de natureza demonstrativa indexical. A fotografia não representa um objeto, mas o designa como um demonstrativo. No caso da fotografia, segundo ele:

A câmera, então, não é usada para representar algo, mas para apontar para isso. (...) A câmera não é essencial àquele processo: um dedo apontando teria igualmente servido. (2008, p. 151).

A atribuição de uma essência indexical à fotografia pode também ser encontrada em autores externos à tradição analítica. Para Roland Barthes, a fotografia "não pode sair dessa pura linguagem dêictica" (1980, p. 14). Com isso, "uma fotografia encontra-se sempre na ponta desse gesto; ela diz: isso, é isso, é aquilo" (idem). A natureza indexical da

\footnotetext{
${ }^{5}$ Uma questão importante a ser levantada é se a fotografia digital, visto que é convertida em um simbolismo, manteria uma conexão causal entre o referente e a imagem fotográfica final. Com relação a essa questão a posição que adotarei é afirmativa, visto que a conversão da imagem fotografada em simbolismo ocorre por meio de um algoritmo. Assim, haveria ainda uma roda causal presente na relação entre a fotografia digital e o referente.
} 
fotografia estaria baseada em seu estatuto como um indice; que significa seu objeto em virtude da conexão causal com ele (cf. Peirce, vol 3, §361). É em decorrência dessa gênese causal que, segundo Barthes, o "referente adere" na foto (1984, p. 16). A fotografia seria como um constante batismo, que tem diante de si o objeto batizado ele mesmo. Por essa razão, para Barthes, a fotografia, ao trazer consigo a marca do representado, teria "algo de tautológico: um cachimbo, nela, é sempre um cachimbo, intransigentemente" (1980, p. 15). A fotografia seria, então, a linguagem pela qual Crátilo esperou por mais de dois mil anos.

A concepção indexical da fotografia (defendida por Scruton e Barthes) tem um profundo paralelo com uma importante vertente interpretativa das memórias episódicas. Segundo Denis Perrin, a concepção indexicalista da memória episódica seria uma forma mais sofisticada de realismo direto (cf. 2012, pp. 21-25). De acordo com o indexicalismo, por meio da memória, o sujeito pode se referir às entidades passadas sem a mediação de uma descrição conceitual do referente. Esse acesso direto ocorreria através do uso de demonstrativo memorial, no qual um termo referencial como "este" ou "aquele" seria utilizado para apontar para um objeto através de uma memória. $\mathrm{O}$ indexicalismo se vale da suposta ligação entre os valores de verdade de um juízo perceptivo passado no tempo presente e um juízo memorial presente de tempo passado (cf. Perrin 2012, pp. 30-32). Nos juízos perceptivos como (1) "esta pessoa [que vejo agora] está cansada" e o juízo posterior (2) "esta pessoa [que me lembro] estava cansada", a verdade do juízo (1) é tomada como condição de possibilidade da compreensão do sentido de (2). Seria necessário um uso correferencial do termo indexical para que houvesse uma ligação nos valores 
de verdade dessas duas sentenças. ${ }^{6}$

No caso da fotografia, a correferencialidade do demonstrativo no ato da tomada da imagem (por ex., "esta pessoa [que vejo agora] está cansada") e o demonstrativo fotográfico ("esta pessoa [que vejo através da foto] estava cansada") estaria garantida pelo modo como a fotografia estaria unida causalmente ao referente.

Uma importante questão a ser levantada é a seguinte: qual concepção do tempo deve ser pressuposta no tratamento da fotografia como familiaridade remota (tanto em sua versão realista direta quanto indexicalista)?

O problema temporal em questão pode ser formulado em termos quantificacionais. A disputa entre diferentes metafísicas do tempo pode ser concebida como uma disputa sobre o que existe em domínios de quantificação irrestrita. A questão central é: "o que existe de forma irrestrita"? (Crisp 2003, p. 201)

Para os presentistas (que defendem uma versão temporal do atualismo modal), apenas objetos e eventos presentes existem (em termos modais, apenas o mundo atual existe) (cf. Meyer 2013, pp. 94-99). O fluxo temporal operaria de modo dinâmico uma constante alteração metafísica no domínio do que existe de forma irrestrita. Segundo Arthur Prior (1967): "algo só é quando ele é presente". Em outros termos: "a presentidade de um evento é apenas o seu acontecer, a sua ocorrência". Assim, nos termos do presentismo de Santo Agostinho (que é locus classicus dessa concepção):

\footnotetext{
${ }^{6}$ Posteriormente, irei propor que, no segundo caso, o termo indexical não é utilizado com função referencial, mas como parte de uma "predicação indexical" (nos termos de Heal (1997) e Zeimbekis (2010)). Esse deslocamento da função referencial para a predicativa estaria presente nas memórias e fotografias - diferentemente do caso no qual o ato indicativo localiza uma entidade espaço-temporalmente no quadro de referências egocêntrico.
} 
se eles são futuro, eles ainda não são; se eles são passados, eles não mais são (cf. Augustine 2006, Book XI).

Para explicitar o estatuto que o passado tem em sua concepção, Prior recorre à distinção entre fato geral e individual (cf. 1968, pp. 17-19). Por exemplo, se eu alego ou acredito que alguém roubou meu lápis, sem que haja um indivíduo específico, acerca do qual eu alego ou acredito, minha crença é sobre um fato geral. De acordo com a terminologia que estamos aqui utilizando, nesse caso, não teríamos um pensamento singular, mas um pensamento geral, acerca de alguém que satisfaria a descrição "x roubou meu lápis". Porém, se a minha crença for sobre um indivíduo específico (por exemplo, que "esta pessoa [que está diante de mim] roubou meu lápis"), essa crença seria sobre um fato individual. Poderíamos, então, ter pensamentos singulares acerca desse particular.

$\bigcirc$ ponto que nos é importante é que os fatos passados seriam, segundo Prior, fatos gerais. Quando nos referimos ao passado, segundo Prior, dizemos que "foi o caso que tal coisa é presente". E quando nos referimos ao futuro, dizemos que "será o caso que tal coisa é presente". A inexistência de fatos individuais passados ficaria evidente no caso do passado que envolve pessoas falecidas. Segundo Prior, a Rainha Ana, uma vez que faleceu em 1714, não é mais uma das entidades particulares, que faz parte da realidade. Podemos, recorrendo a proposições gerais, dizer que: "foi o caso que existe uma pessoa chamada 'Ana', que reinou sobre a Inglaterra, etc., mas não há agora tal pessoa". Porém, não há fato individual algum que atualmente tenha a Rainha Ana como constituinte (vetando, assim, a possibilidade que viéssemos a ter pensamentos singulares sobre a Rainha Ana - nos quais ela seria parte do conteúdo da proposição). 
Em oposição ao presentismo, os eternalistas (que sustentam uma versão temporal do realismo modal) defendem que o tempo é a ordem estática das posições (instantes ou eventos), ordenados pelas relações de "antes" e "depois". Por esse viés, o domínio de quantificação é atemporal e nada vem a ser ou deixa de ser (em termos modais, todo mundo possível é igualmente real). ${ }^{7}$ Nos termos formulados por Prior, haveria fatos individuais passados, assim como fatos individuais presentes e futuros.

Kendall Walton chega a tocar no problema da quantificação, sem se dar conta da possível relação entre esse problema e a dimensão temporal da concepção por ele adotada. Ele nega que possamos literalmente ver unicórnios representados em uma tapeçaria. Poderíamos apenas dizer que vemos ficcionalmente unicórnios. A razão por ele oferecida é que: "não há unicórnios; assim eles não estão realmente vendo um" (WALTON 2008, p.25).

Caso adotássemos uma forma de presentismo ontológico (no qual algo deixa de existir ao deixar de ser presente), não poderíamos posteriormente "ver" o objeto ele mesmo através de uma foto - como no caso da citação de Walton acerca de seus parentes falecidos. Para viabilizar a familiaridade remota temporal é necessário pressupor uma metafísica do tempo na qual as entidades passadas, depois de serem presentes, ainda continuam a existir como parte da ordem temporal da realidade. Em outros termos: visto que uma relação cognitiva com particulares não pode ocorrer sem um relata, seria então necessário pressupor o

\footnotetext{
${ }^{7}$ Isso gera a dificuldade de como expressar a não mais existência de uma entidade particular; como, p. ex., no caso da morte de um indivíduo. Cocchiarella (2007), ao optar pelo uso atemporal da quantificação, introduz um segundo quantificador "E!", cujo domínio são as entidades que presentemente existem (cf. pp. 34-35).
} 
realismo metafísico do passado. ${ }^{8}$

\section{CRÍTICA AO TRATAMENTO DA FOTOGRAFIA COMO FAMILIARIDADE REMOTA}

Temos agora os elementos necessários para formular o problema em termos lógicos: de acordo com a concepção da fotografia como familiaridade remota, qual seria a função lógica desempenhada pelas fotografias nos pensamentos acerca de entidades conhecidas exclusivamente através de fotografias?

Uma vez pressuposta a metafísica do tempo que garanta a existência de entidades no passado, a fotografia deveria poder desempenhar uma importante função referencial nos pensamentos que temos acerca das entidades conhecidas exclusivamente a partir de fotografias. Visto que através da foto teríamos um acesso cognitivo ao objeto ele mesmo, deveríamos então poder ter pensamentos singulares, nos quais a entidade ela mesma ocuparia a parte nominal do pensamento. Em outros termos, deveríamos poder ter pensamentos objetos-dependentes nos quais o Princípio de Russell seria respeitado - expresso por Gareth Evans (1982), de que no pensamento singular devemos saber qual particular temos em mente (retornaremos a esse ponto a diante).

Em um artigo de 2006, Paulo Faria utiliza um argumento, que recorre a um exemplo, destinado a mostrar que, em alguns casos, temos "a ilusão de ter um pensamento singular" (Faria 2006, p. 111). A ideia expressa no

\footnotetext{
${ }^{8}$ Esse realismo pode ser encontrado no eternalismo ou na teoria do "bloco-crescente" ("growing block theory" - como sustentada, por exe., por C. D. Broad (1923)). Visto que essa concepção não oferece uma linha de resposta promissora ao paradoxo de McTaggart (como o próprio McTaggart atesta em 1927) e o debate metafísico encontra-se polarizado entre eternalistas e presentistas, a teoria do "bloco crescente" não seria aqui explorada.
} 
argumento é que podemos repetidamente usar um demonstrativo para nos referirmos a um objeto, sem que tenhamos ciência de que, cada vez que nos referimos ao objeto, estamos diante de um objeto distinto. Assim, ao pensarmos posteriormente no objeto através de um demonstrativo, teríamos a ilusão de ter um pensamento singular. Por exemplo, ao dizermos posteriormente algo do tipo "aquele objeto tal e tal coisa", a expressão "aquele objeto" não seria um termo singular, mas uma descrição definida (como "o objeto que venho observando") (cf. Faria 2006, pp. 111112). Nesse caso, segundo Faria, perdemos "a 'ancoragem' do pensamento de re no objeto correspondente" (2006, p. 112).

Em um artigo de 2010, Paulo Faria utiliza o mesmo argumento para mostrar as razões que levariam Russell a abandonar a concepção da memória como familiaridade remota, presente no realismo direto:

A memória como familiaridade retida [retained acquaintance], em uma palavra, não é suficientemente memória, uma vez que falha em realizar a tarefa atribuída ao conhecimento por familiaridade: garantir a satisfação do Princípio de Russell. (2010, p. 168).

Zeimbekis formula, em um artigo de 2010, semelhante argumento destinado a mostrar que, caso fiquemos restritos ao conteúdo da imagem fotográfica, não haveria a determinação da identidade numérica do referente. Consequentemente, a percepção de fotografias não nos permitira pensamentos nos quais o Princípio de Russell seria respeitado.

$\mathrm{O}$ argumento de Zeimbekis pode ser reformulado nos 
seguintes termos. ${ }^{9}$ Ao pensarmos acerca de um objeto que nos é dado na percepção, a determinação de qual particular temos em mente, ocorre de dois modos. Diante de uma dúzia de objetos qualitativamente idênticos (p. ex., doze bolas azuis (figura 1)), o domínio da percepção não será todos os objetos que têm essas propriedades, mas apenas aqueles que estão diante de nós. Há aqui uma restrição de fato do domínio. Além disso, e mais significativamente, podemos localizar no espaço e no tempo o particular ao qual estamos nos referindo pelo demonstrativo "este" (ou "isso"), distinguindo-o numericamente dos demais. Nos termos de Evans e Strawson, podemos identificar demonstrativamente o objeto e, com isso, teríamos a capacidade de distinguir o objeto em pensamento de todas as outras coisas (cf. (Evans 1982, pp. 143-204) e (Strawson 2003, pp. 19-20)). Nesse caso, teríamos um "pensamento singular baseado na percepção" (cf. Zeimbekis (2009, p. 87) e (2010, p. 15)). A determinação do referente não ocorrerá por meio de uma identificação baseada na aparência do objeto, mas pela localização do referente no quadro de referência egocêntrico, dentro do domínio restrito da percepção.

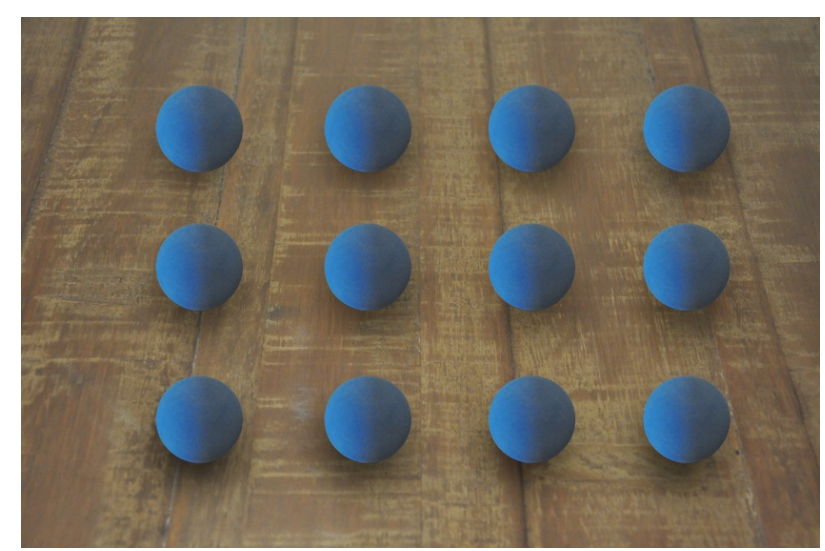

(Figura 1).

\footnotetext{
${ }^{9}$ Adaptarei o exemplo de Zeimbekis que recorre a duas fotos de irmãos gêmeos (cf. 2010, p. 17).
} 
Mas imaginemos agora que temos diante de nós a fotografia de um desses objetos, qualitativamente idênticos (p.ex., uma foto de uma bola azul (figura 2)). Saberíamos qual dos objetos é o referente da foto, de tal modo que pudéssemos ter pensamentos singulares acerca daquele objeto particular? Zeimbekis formula essa questão nos seguintes termos (em problema que ele formula em relação a Dominic Lopes): poderíamos "reconhecer particulares exclusivamente com base na percepção de fotografias "? (Zeimbekis 2010. p,15) Evans formula semelhante questão em seu livro de 1982, nos seguintes termos: "é possível identificar demonstrativamente um objeto visto em uma fotografia"? (Evans 1982, p. 92)

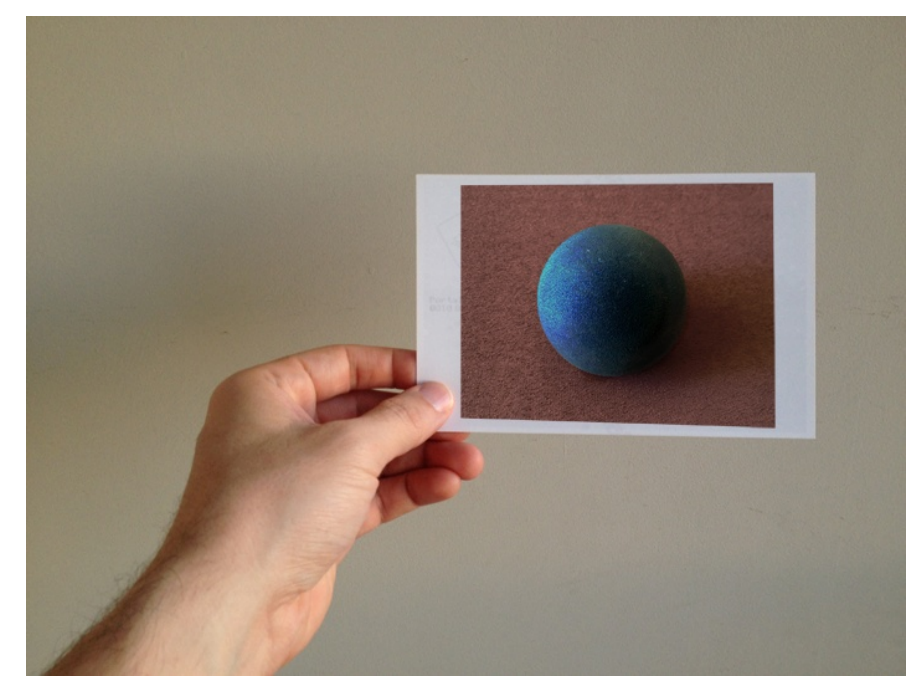

(Figura 2)

A resposta de Zeimbekis a esse problema é negativa e traça uma importante distinção entre dois níveis: i) o conteúdo da percepção pictórica (que podemos chamar, nos termos de Evans, de "conteúdo da fotografia" (Evans, 1982, p. 125) e ii) crenças acerca da história causal da fotografia como objeto (que podemos denominar de crenças metarepresentacionais).

No exemplo adotado, o conteúdo da fotografia poderia 
ser expresso nos seguintes termos (adaptando aqui o exemplo de Evans de 1932, p.125):

Azul(x) \& Bola(x) \& Marrom(y) \& Quadrado(y) \& $(\mathrm{x})$ Em cima de $(y)^{10}$

O ponto explorado por Zeimbekis é que, caso fiquemos restritos ao conteúdo da fotografia da bola azul, não saberíamos acerca de qual particular estamos pensando. Inúmeras entidades podem satisfazer essa mesma descrição. Isso mostraria que a percepção de fotografias não nos permitiria pensamentos singulares. Embora tenhamos a crença metarepresentacional de que objeto numericamente distinto esteve diante da câmera, no ato da tomada da imagem, não sabemos a partir do conteúdo qual é esse objeto. É a crença meta-representacional que torna o conteúdo da fotografia uma proposição quantificada, na qual haveria o comprometimento de que foi o caso que existe um único $x$ e um único $y$ que satisfazem a descrição "Azul(x) \& Bola(x) \& Marrom(y) $\&$ Quadrado(y) \& (x)Em cima de(y)". ${ }^{11}$ Contudo, o que importa ser notado é que a atribuição de uma identidade numérica do referente não ocorre no nível i) do conteúdo da fotografia, mas no nível ii) das crenças metarepresentacionais.

A tese sustentada por Zeimbekis é que seriam as crenças relacionadas à fotografia como objeto (que extrapolam o conteúdo da fotografia) que ancoram a referência do conteúdo da fotografia. De acordo com ele: "tal conhecimento do

\footnotetext{
${ }^{10}$ Evans faz a seguinte ressalva: "certamente o conteúdo de mesmo a fotografia mais simples será muito mais complexo que isso. (Será algo que pode ser especificado conceitualmente apenas com alguma perda". Além disso, afirma o autor: "eu não creio que a especificação do conteúdo da fotografia deva fazer referência ao objeto ou objetos que ela é de [reference to the object or objects that it is of]". (1982, p.125)

${ }^{11}$ É essa quantificação que insere uma diferença crucial entre a fotografia e outros meios de representação por imagem, como a pintura e o desenho.
} 
meio é independente dos conteúdos perceptivos causados pelas imagens" (Zeimbekis 2010, p. 21).

Agora digamos que eu seja o autor da foto e saiba qual dos objetos foi o objeto retratado. Nesse caso, conheço a história causal da foto e poderia, ao olhar posteriormente para ela, ter um pensamento singular acerca daquele objeto particular (pois sei qual objeto foi fotografado). O que possibilita ter o pensamento singular, nesse caso, não é o conteúdo da fotográfica, mas o meu conhecimento de sua história causal. Ou seja, caso eu aponte para a foto e diga "este objeto é tal que...", a determinação da parte nominal da sentença (de qual objeto estamos pensando acerca de) não ocorrerá através do conteúdo da foto, mas por meio de um conhecimento exterior à fotografia (o meu conhecimento direto do referente que foi fotografado). A conclusão de Zeimbekis é que:

Os conteúdos das fotografias não proveem eles mesmos o tipo de informação numérica e contextual requerida pelo pensamento singular. A referência da fotografia é ao invés disso garantida por crenças independentes ou comunicação linguística sobre a história causal da fotografia como objeto. Em outras palavras, são crenças sobre a identidade numérica das fotografias como objetos que ancoram a referência dos conteúdos representacionais das fotografias. (2010, p. 11)

Mas quais seriam as crenças meta-representacionais (sobre sua história causal) que temos ao olharmos para uma fotografia?

Ao concebermos uma dada imagem como uma fotografia, pensamos que, em algum momento do passado, objetos ou pessoas estiveram diante da câmera fotográfica e que alguém operou a ação de tirar a foto. No ato da tomada da imagem ocorreu uma relação causal entre a imagem dos objetos (ou pessoas) e algum material foto-sensível (ou sensor 
foto-elétrico). Isso foi posteriormente revelado, impresso ou eletronicamente processado e distribuído. Caso não haja manipulação dos processos de tomada e distribuição da imagem que distorçam o resultado final, temos a crença de que a imagem resultante tem aspectos visuais semelhantes à entidade que esteve diante da câmera no ato da tomada da imagem.

Ao recorrer à distinção entre conteúdo da fotografia e crenças meta-representacionais, minha intenção não é negar que a fotografia tenha uma história causal que a torne, nos termos de Evans e Kaplan, de ("of") um objeto (cf. (Kaplan 1968, p. 198) (Evans 1982, p. 124-125)). É essa história causal que fixa qual é o referente da foto. Contudo, como sugere Kaplan, uma fotografia pode ser de uma pessoa ("of a person") sem que seja semelhante ("resembles") à pessoa (1968, pp. 198-199). A relação de semelhança (que pode ou não ocorrer), nesse caso, seria entre o conteúdo da fotografia e as propriedades visuais do referente causal da fotografia. Isso permite conceber a fotografia, nos casos em que seu uso tem pretensões epistêmicas, como uma representação que pode ou não corresponder ao seu referente causal, sendo assim, verdadeira ou falsa. ${ }^{12}$

$\mathrm{O}$ argumento aqui delineado tem como ponto central a ideia de que (caso aceitemos a possibilidade de pensamentos singulares e o Princípio de Russell (e esse é um ponto em disputa que um externalista poderia não conceder)) a percepção do conteúdo de fotografias não nos permitiria

\footnotetext{
${ }^{12}$ Com isso, não pretendo deixar de lado a distinção entre linguagem e fotografia. Nem todo uso que fazemos da fotografia visa expressar um conteúdo proposicional, que poderia ser verdadeiro ou falso. Muitos usos da fotografia têm em vista a expressão artística. Mas, ainda assim, nesses casos, seria possível a indagação acerca do sentido do ato de fala (speech-act) do artista por meio da foto (cf. LOPES 1996, p.67-8.).
} 
pensamentos singulares, pois o conteúdo não garantiria a satisfação do princípio. Ou seja, há uma diferença fundamental a ser traçada entre os pensamentos que têm por base a percepção e os pensamentos que têm por base a percepção de fotografias. Isso sugere a incorreção do tratamento da fotografia como familiaridade remota, que a concebe como uma forma de percepção prostética.

No caso da fotografia, temos a crença metarepresentacional de que há um e somente um objeto que esteve diante da câmera no ato da tomada da imagem. Tal crença pode ser falsa e a imagem fotográfica ser fruto de manipulações. Além disso, mesmo que não haja manipulações, não se segue automaticamente que a imagem fotográfica final seja semelhante visualmente ao objeto retratado (isso dependerá de vários fatores que dizem respeito ao equipamento, ao enquadramento, à fotometria etc.). Contudo, caso sejam utilizados equipamentos que não distorçam as proporções e cores dos objetos e não haja manipulação dos processos de tomada e revelação da imagem que desvirtuem o resultado final, ainda assim, o conteúdo da imagem (de acordo com o argumento de Zeimbekis), causado pela relação direta com o próprio objeto, não seria suficiente para que soubéssemos acerca de qual particular estamos pensando, no ato da percepção da fotografia. Nos termos de Paulo Faria, seria possível dizer que na fotografia temos apenas "a ilusão de ter um pensamento singular" (2006, p. 111).

\section{A FOTOGRAFiA COMO PARTE DE UMA PREDICAÇÃO INDEXICAL}

Mas se a percepção do conteúdo da fotografia não determi- 
na a identidade numérica do referente, quais são os papéis desempenhados pela fotografia e pelo demonstrativo, nos casos nos quais tomamos fotos como modelos, em predicações do tipo "este é o tal-e-tal" (apontando para uma fotografia)? Se através do demonstrativo "este" não estamos apontando para um particular, qual é o sentido dessa proposição e a função lógica do demonstrativo?

Segundo Paulo Faria, quando perdemos a ancoragem do pensamento singular e temos apenas a ilusão de ter tal pensamento, o uso de um demonstrativo não seria um termo singular, mas uma descrição definida (cf. Faria 2006, p. 111). Semelhante tratamento pode ser encontrado em Zeimbekis, no caso da fotografia. $\mathrm{O}$ autor propõe o emprego da noção de "predicação indexical", cunhada por Jane Heal, nas predicações do tipo "este é o tal-e-tal", que tomam fotografias como referentes do ato indicativo. A ideia central de Heal (1997) é que os indexicais não apenas são utilizados em expressões referenciais, que determinariam a parte nominal da sentença (aquilo sobre o qual estamos falando), mas também em expressões predicativas, determinando conteúdos predicativos.

Em uma situação normal, utilizamos a sentença "este é o meu avô", da seguinte forma. Caso estivéssemos diante de várias pessoas, poderíamos utilizá-la, acrescida do ato ostensivo, para mostrar a alguém, quem é o meu avô. Com isso, o termo demonstrativo "este" passa a ter como conteúdo o particular localizado no espaço egocêntrico e no tempo simultâneo ao ato ostensivo. Mas o mesmo não pode ser o caso quando proferimos a sentença utilizando a foto como referente da ostensão. Aquele pedaço de papel (o objeto localizado no espaço egocêntrico) não é o meu avô. Além disso, como visto, o conteúdo da fotografia não determina- 
ria a identidade numérica do referente. Com isso, o ato ostensivo, que aponta para a imagem, falharia em localizar o referente do termo singular. O resultado disso é que, ao tratarmos o "este" como tendo o papel de singularizar um particular através da foto, a sentença seria então desprovida de sentido (pois as sentenças demonstrativas são objetosdependentes e não há a determinação da identidade numérica do referente pelo conteúdo da fotografia). Em outros termos: a função lógica do demonstrativo não poderia ser determinar a parte nominal da sentença (aquele sobre o qual pensamos).

Para Zeimbekis, o uso de fotografias como modelos, em predicações demonstrativas, seria semelhante ao caso das predicações indexicais de Heal. Quando dizemos, apontando para uma fotografia, "este é o meu avô", o demonstrativo "este" não seria utilizado para identificar um particular, acerca do qual se fala, mas para identificar propriedades perceptuais/fenomenais/visuais exemplificadas pela foto e que fazem parte do predicado que atribuímos a um referente por descrição. A função lógica do demonstrativo seria deslocada da função referencial para a predicativa. $O$ "este" não identificaria a parte nominal da sentença, mas conteúdos da parte predicativa. Assim, a função lógica da fotografia seria a de exemplificar propriedades fenomenais e o termo demonstrativo teria a função de indicar essas propriedades, atribuídas por descrição a uma entidade que não conhecemos por familiaridade através da foto.

Ao apontar para uma foto e dizer "este é o meu avô", quer-se, com isso, afirmar que o avô tem (ou tinha, em um determinado momento do tempo) semelhantes propriedades fenomenais às exemplificadas pela foto. A compreensão desse conteúdo predicativo dependerá da capacidade do in- 
terlocutor de conhecer o método de projeção (o sistema de representação), que possibilite tomar as formas bidimensionais presentes na fotografia como representação das propriedades visuais do referente. Os sistemas de representação da fotografia especificariam os princípios do mapeamento (os métodos de projeção) das propriedades visuais exemplificadas na fotografia sobre o domínio dos referentes, determinando o conteúdo da fotografia (de modo semelhante à proposta de Nelson Goodman em Languages of Art). ${ }^{13}$

Já a determinação da parte nominal (qual é o referente que tem aquelas propriedades) teria de ser feita por algo que extrapola o conteúdo da fotografia (por meio do conhecimento da história causal da foto, ou por familiaridade com o referente etc.). É a necessidade da determinação da parte nominal que se expressa no uso de títulos e legendas para as fotografias.

Com isso, caso queiramos dizer que a fotografia nos permite alguma forma de familiaridade, poderíamos dizer que ela nos permite familiaridade com propriedades fenomenais. Mas ela não nos permitiria familiaridade com entidades particulares fotografadas. Nosso conhecimento dessas entidades, no caso da fotografia, seria apenas por descrição.

\section{CONCLUSÃO:}

Podem então concluir que há uma profunda diferença en-

\footnotetext{
${ }^{13}$ Cf. GOODMAN 1976. Contudo, diferentemente do que defende Goodman, a ideia aqui explorada estaria próxima da posição que Lopes qualifica como "compatibilista", na qual o uso da linguagem como modelo para a compreensão da imagem não seria contrária á explicação perceptual da imagem (cf. LOPES 1996, p. 56).
} 
tre a função lógica do demonstrativo em juízos perceptivos e em juízos que tomam fotografias como modelos. Nos juízos (1) "esta pessoa [que vejo agora] está cansada" e o juízo posterior (2) "esta pessoa [representada na fotografia] estava cansada", o demonstrativo em (1) teria uma função referencial, embora em (2) uma função predicativa. Ou seja, ao apontarmos para uma foto e afirmarmos, por exemplo, que "este é o tal-e-tal", queremos dizer que:

- Foi o caso que existe um x que é único [conteúdo meta-representacional - baseado na crença da gênese causal da fotografial (podendo ou não essa entidade ainda existir no presente)

- esse x tem a propriedade tal-e-tal [predicado verbal]

- e o x tem estas propriedades fenomenais [predicado fenomenal exemplificado pela foto e dimensão indexical predicativa]

Uma das vantagens do abandono da tese da fotografia como familiaridade remota é que nos afastaria da metafísica do tempo, que pressupõe a existência de particulares no passado. Isso permite a adequação do tratamento da fotografia como conhecimento por descrição à metafísica do tempo presentista (nos moldes de Arthur Prior). ${ }^{14}$ Visto que o conhecimento por descrição é objeto-independente, não é necessária a existência da entidade particular descrita da fo-

\footnotetext{
${ }^{14}$ Uma consequência dessa concepção, como explora Dummett (1969), é que a determinação do valor de verdade de uma proposição sobre o passado não ocorreria por meio de um fazedor de verdade situado no passado (o fato individual descrito), mas por meio daquilo que no presente contamos como determinante da verdade ou falsidade dessa proposição (relatos históricos, indícios etc.). Ou seja, ao adotarmos o presentismo seríamos levados a adotar uma forma de antirrealismo para as proposições sobre o passado.
} 
to. Com isso, seria possível uma inversão da intencionalidade temporal normalmente atribuída a elas. A fotografia não seria um demonstrativo que aponta para particulares no passado ou um modo de percepção do passado. A fotografia seria a exemplificação no presente de propriedades fenomenais, que atribuímos por descrição a alguma entidade, que já foi presente (no ato da tomada da fotografia). Ou seja, ela pode ser concebida como a instanciação no presente, de propriedades fenomenais de algo que (ao se tornar passado) deixou de ser.

Abstract: The main objective of this paper is to understand the logic role played by photographs in thoughts about entities known only through photographs. I will contrast two general interpretative lines: photography as knowledge by acquaintance and as knowledge by description. The analyses of those interpretations will take into account possible relations with discussions about metaphysics of time and episodic memory. Throughout the paper I will criticize the treatment of photography as acquaintance, based on John Zeimbekis' interpretation. In its treatment as acquaintance, photography would play the logical role of a demonstrative that points to a particular entity in the past, through the causal route that links the photograph to its referent. The criticism of this concept has as its starting point the distinction between the causal referent of the photograph and its representational content (the visual properties exemplified by the photograph). The thesis here developed (along the lines proposed by Zeimbekis) is that the photographic content would not be sufficient to determine the numerical identity of the referent. Thus, it will be proposed a shift of the logic role played by photography from a referential role to a predicative. Photograph would exemplify phenomenal properties attributed to an entity known only by description.

Keywords: knowledge by acquaintance; knowledge by description; singular thought; metaphysical realism of the past; presentism.

\section{REFERÊNCIAS}

Augustine, S. Confessions. Penguin Books, New York, 2006.

Barthes, Roland. A câmara clara. Rio de Janeiro: Nova Fronteira, 1984. 
Bourne, C. A Future for Presentism. Clarendon Press, Oxford, 2006.

Broad, C. D. Scientific thought. New York: Harcourt, Brace and Co., 1923.

Campbell, J. Past, Space and Self. The MIT Press, Cambridge, 1994

. "The Structure of Time in Autobiographical Memory", European Journal of Philosophy 5 (1997), 105 118.

CRISP, T. "Presentism", in: The Oxford Handbook of Metaphysics. ed. Loux and Zimmerman, Oxford: Oxford University Press, 2003, pp. 211-245.

Cocchiarella, N. Formal Ontology and Conceptual Realism. Series: Synthese Library, Vol. 339, Dordrecht, 2007.

Dummett, M. "The Reality of the Past", in. Truth and Other Enigmas. Duckworth, 1969, pp. 358-374.

Evans, Gareth. The varieties of reference. McDowell, J. (Ed.). Oxford Clarendon Press, 1982.

Faria, P. "A preservação da verdade". O Que nos Faz Pensar (PUCRJ), v. 20, p. 101-126, 2006.

. "Memory as acquaintance with the past", Kriterion, Belo Horizonte, nº 121, Jun./2010, p. 149-172.

GOODMAN, A. Languages of Art: An Approach to a Theory of Symbols. 2nd ed. Indianapolis: Hackett, 1976.

Heal, Jane. "Indexical Predicates and Their Uses", Mind 106 (1997): 619-640. 
Kaplan, D. "Quantifying in". Synthese 19, Dordrecht. 1968, pp. 78-214.

LEWIS, David. The Plurality of Worlds. Oxford, Blackwell, 1986.

Meyer, U. The Nature of Time. Oxford University Press, 2013.

McTaggart, J. The Nature of Existence. Volume II. Cambridge: At the University Press, 1927.

LOPES, D. Understanding Pictures. Oxford: Oxford University Press, 1996.

Peirce, Charles Sanders. Collected papers, Cambridge (Mass.), Harvard University Press, 8 vols., de 1931 a 1958.

Perrin, Denis. Qu'est-ce que se souvenir. Vrin, Paris, 2012.

Prior, Arthur. Past, Present, and Future. Oxford University Press, 1967.

1968.

. Papers on Time and Tense. Oxford University Press,

Russell, Bertrand. "Knowledge by Acquaintance and Knowledge by Description", in. Mysticism and Logic and Other Essays. Longmans, London, Green \& Co, 1918, pp. 197-218. First published in PAS, Vol. 11 (1910-11), 10828.

. The Problems of Philosophy. New York, Oxford University Press, 1959. First published in the Home University Library, 1912.

Scruton, Roger, "Photography and Representation". In: 
Walden, S. (ed), Photography and Philosophy Essays on the Pencil of Nature, Walden (ed), Blackwell Publishing, Oxford, 2008, pp. 138-166.

SILVA, G. "O fim da fenomenologia em Wittgenstein uma abordagem temporal". Revista Philósophos, v. 18, p. 11-41, 2013.

. "Russell and Wittgenstein on time and memory: two different uses of the cinematographic metaphor". Analytica (UFRJ), v. 18, p. 197-227, 2015.

Strawson, P. Individuals. London, Routledge, 2003.

Zeimbekis, J. "Pictures and Singular Thought", The Journal of Aesthetics and Art Criticism, 68:1 Winter 2010.

. "Pictures as Incomplete Representations", Proceedings of the European Society for Aesthetics, vol. 1, 2009, pp. 77-89.

Walton, Kendall. " Transparent Pictures: On the Nature of Photographic Realism", in. Photography and Philosophy Essays on the Pencil of Nature. In: Walden (ed), Blackwell Publishing, Oxford, 2008, pp. 14-49. 